\title{
Epidemiologic and Histopathologic Feature of Lung Cancer in Central Iran (2012-2018)
}

\author{
Mohammad Sadegh Khalilian ${ }^{1,2}$, Sina Narrei ${ }^{2}$, Mahdi Hadian ${ }^{1,2}$, Mehrdad \\ Zeinalian $^{2,3 *}$
}

1. Student Research Committee, Isfahan University of Medical Sciences, Isfahan, Iran

2. Ala Cancer Prevention and Control Center, Isfahan, Iran

3. Department of Genetics and Molecular medicine, School of Medicine, Isfahan University of Medical Science, Isfahan, Iran (Corresponding author): zeinalianmehrdad@gmail.com

\section{Abstract}

Background: Lung cancer is one of the common causes of death worldwide. Although the incidence rate of lung cancer in Western countries is decreasing, it presents a growing trend in developed countries. Since there is no accurate enough information about the epidemiological and Histopathologic features of lung cancer in central Iran, Isfahan, we were motivated to conduct this research.

Materials and Methods: This was a descriptive, cross-sectional study carried out in central Iran, Isfahan. All demographic, histopathological and clinical data of the lung cancer patients registered in MACSA, a referral charity-based cancer center in central Iran, was analyzed within 2012-2018 using SPSS v.22 software.

Results: Altogether 260 patients with lung cancer were included in this study from 6127 cancer patients registered within 2012-2018 (4.2\%). Out of them, $66.2 \%$ were men, and $18.8 \%$ of the patients were alive at the time of the study. The mean age of the patients at diagnosis was $61.56(\mathrm{SD}=14.11$, range: 9-93). Altogether, $63.1 \%$ of patients had metastasis of whom $57.6 \%$ were in stage IV at diagnosis. The Frequency of different types of lung cancer was $36.9 \%$ adenocarcinomas, $14.2 \%$ squamous cell 
carcinoma, 9.6\% bronchogenic carcinoma and 8.1\% small cell lung cancer, respectively. Altogether, 128 cases were smokers with an average $35.45 \pm 14$ packyears. Only in $36.2 \%$ of the patients, the diagnostic and therapeutic biomarkers had been checked, and CK7 was positive in $88.9 \%$ of the cases in which the biomarker had been checked.

Conclusion: Despite to similar Iranian studies, the most common histopathologic type of lung cancer among the patients was adenocarcinoma that it may be attributed to the lower consumption of smoking in our population and their different genetic context. Molecular biomarkers had been checked in a small portion of the patients. More education of the clinicians along with the development of cancer molecular testing may lead to promote the personalized-based approach.

Key word: lung cancer, Epidemiology, Histopathology, Central Iran, Isfahan

\section{Introduction}

Cancer is the second leading cause of death in developed countries and the third one in developing countries like Iran(1,2). The incidence of cancer in developing countries is increasing due to the population aging and the raising of some lifestyle-related cancer risk factors like smoking, physical inactivity, obesity, stress, etc. Cancer is the third most common cause of mortality after cardiovascular disease and car accidents in $\operatorname{Iran}(3)$.

Lung cancer is one of the common causes of death worldwide (4). Lung cancer affects more than a million people a year, according to the International Agency for Research on Cancer (IARC). Because of the high mortality rate of lung cancer, scientists pay more attention to its diagnosis, treatment, and prognosis (5). In the United States, lung cancer is the second most common cancer among men and women (6). Moreover, lung cancer is the third most common cancer in both genders with the highest rate of death in Europe (7). Although the incidence rate of lung cancer is estimated low in Iran, its survival rate is not promising (8). 
Lung cancer is usually divided into two groups: small cell lung cancer (SCLC) and nonsmall cell lung cancer (NSCLC). NSCLCs accounts for about $85 \%$ of all lung cancers and are classified into squamous cell carcinoma (SCC), adenocarcinoma (AC), and large cell carcinoma (9). The epidemiology of lung cancer is changing in many parts of the world, as we enter the 21 st century. The incidence trend of lung cancer is not promising, however, it moves from developed to less developed countries (10). However, the relationship between smoking and various types of histological findings of lung cancer is not similar, so there is a significant relationship between smoking and the occurrence of SCLC and SCC, but its association with adenocarcinoma is lower (11).

There are Limited epidemiologic studies on lung cancer in Iran. Some studies show that the incidence of lung cancer may be increased by changes in the smoking pattern. The incidence of lung cancer in the North West and West provinces of Iran has been estimated higher than other regions (12). Since there is no accurate enough information about the epidemiological and Histopathologic feature of the lung cancer in central Iran, Isfahan, we were motivated to conduct this research.

\section{Materials and Methods}

This was a descriptive, cross-sectional study carried out in Ala cancer control and prevention center (MACSA), a charity-based institute for supportive and palliative care of cancer in central Iran, Isfahan. All the patients registered in MACSA have an electronic database including clinical and para-clinical information. In this study, demographic, histopathological and clinicopathological information of all patients with lung cancer admitted to MACSA was obtained from 2012 to 2018. Demographic variables included age at diagnosis, age at death, gender, and location of living. Moreover, some cancer-related risk factors such as smoking (cigarette, opium or Hookah), alcohol addiction, and chronic contact with chemical substance were also included. Histopathological variables including pathologic feature, metastasis state, the tumor stage, type and size, and the tumor biomarkers were also assessed. Moreover, 
clinicopathological factors containing the first main symptom, past medical history, the family history of cancer and the type of treatment were included. The collected data was analyzed to determine the statistical information and correlations by SPSS v.22 software.

\section{Results}

Altogether among 6127 cancer patients registered in MACSA within 2012-2018, 260 patients with lung cancer (4.2\%) were included in this study. Out of this population, 172 $(66.2 \%)$ were men, and $49(18.8 \%)$ patients were alive at the time of the study. The male to female ratio is 1.95 . Overall, 242 patients $(93.1 \%)$ were urban residents, and the others $(6.9 \%)$ were rural. The average age of the patients at diagnosis was $60.30(\mathrm{SD}=14.31,9$ 93 ), and at the time of death 62.59 ( $\mathrm{SD}=13.71)$. Moreover, the mean period time from diagnosis to death was $13.36(\mathrm{SD}=12.31)$ months.

Out of total lung cancer patients, 135 cases (51.9\%) had a positive family history of cancer of whom $92(68.1 \%)$ cases have at-least a first-degree relative with cancer. The most common malignancies among the affected family members were in lung (32, $23.7 \%)$, breast $(17,12.6 \%)$ and stomach $(17,12.6 \%)$, respectively. (Table 1)

Altogether, $164(63.1 \%)$ and $150(57.6 \%)$ patients had metastasis at the time of study and diagnosis, respectively (Table 2$)$. The common sites of metastasis were bone $(73,44.5 \%)$, brain $(60,36.6 \%)$ and liver $(31,18.9 \%)$, respectively.

According to the pathological reports, the Frequency of different types of lung cancer were $96(36.9 \%)$ cases of adenocarcinomas, $37(14.2 \%)$ cases of squamous cell carcinoma, $25(9.6 \%)$ cases of bronchogenic carcinoma and $21(8.1 \%)$ cases of small cell lung cancer, respectively.

The histopathological feature of the studied malignancies were categorized in four types include: $21 \operatorname{SCLC}(8.1 \%), 162 \operatorname{NSCLC}(62.3 \%), 51$ cases other types of lung cancer $(19.6 \%)$ and 26 cases $(10 \%)$ unknown. In the unknown category the pathological feature of the patients' tumors had not been identified (Table3). Overall, $41 \%$ of the tumors were located in the left side, $37.2 \%$ in the right side and $16.7 \%$ in the bronchi of lung. 
Out of 260 patients, 128 cases $(49.2 \%)$ were smokers with an average $(35.45 \pm 14)$ pack per year.

The exposure rate of the patients with some of the environmental factors investigated in this study listed in Table 4. According to our study, 125 (72.6\%) of men and 3 (3.4\%) of women were active cigarette smoker.

The most common early symptoms in the patients were cough $(209,80.4 \%)$, dyspnea (31, $11.9 \%)$, hoarseness $(11,4.2 \%)$ and hemoptysis $(9,3.5 \%)$, respectively. Moreover, 158 cases $(60.8 \%)$ had a history of a chronic disease, including 40 (25.3\%) patients with ischemic heart disease, 37 (23.4\%) with diabetes and 49 (31\%) with hypertension.

Also, a history of COPD (Chronic Obstructive Pulmonary Disease), Asthma, and TB (Tuberculosis) has been reported for $4(1.5 \%), 2(0.8 \%)$ and $1(0.4 \%)$ patients, respectively.

Radiation or chemo-procedures for therapeutic or palliative intention had been done for $175(67.3 \%)$ patients of whom 95 patients $(54.3 \%)$ had tolerated palliative chemotherapy, and 80 patients $(45.7 \%)$ had received therapeutic chemotherapy. Radiation therapy had been done for 160 patients of whom 99 cases $(61.9 \%)$ were therapeutic and the others were palliative.

Altogether, 53 molecular biomarkers had been checked by Immunohistochemical (IHC) staining of tumor samples. The most common biomarkers have been listed in Table 5 .

\section{Discussion}

\section{Epidemiology}

Although the incidence rate of lung cancer in Western countries is decreasing, it presents a growing trend in developed countries (13). According to the some previous studies, it seems the incidence rate of lung cancer in Iran is lower than Western countries (6). The national reports have showed that the prevalence of lung cancer is ranked as seventh or eighth among men and above the tenth among women, while on the global scale, it is the first in men and fourth in women (14). This retrospective study was conducted on the 260 
patients with lung cancer out of 6127 cancer patients registered in MACSA within 20122018. The aim of this study was to investigate the epidemiological and histoclinicopathological features among the lung cancer patients in central Iran.

According to the previous studies in Iran, male to female ratio has been reported 2.85 (12), 3.22 (15) and 5.09 (16), while in our study it was 1.95. In other countries like Spain and India the ratio was 8.1 (17) and 4.1 (18) respectively. The lower male to female ratio with the lung cancer compared with other countries can be due to difference in environmental exposures of Iranian women, also, some probable genetics variations. Further investigations based on the risk assessment are highly recommended for this population.

In our study, the mean age of the patients at the time of study was $61.5(\mathrm{SD}=14)$. According to the results of other studies in Iran the mean age of the patients were 65.7 $(\mathrm{SD}=11.2)(16), 59.9(\mathrm{SD}=13)(19)$ and $64.09(\mathrm{SD}=9.44)(20)$. In studies at other countries like India (21) and Canada (22) the mean age of the patients were 56 and 75years respectively .This can be attributed to the different genetic context and environmental and lifestyle-related factors (15). The mean age at time of study among men $(61.69, \mathrm{SD}=12.84)$ and women $(61.30, \mathrm{SD}=16.39)(\mathrm{P}=0.041)$ were similar to the studies at Tehran $(\mathrm{P}=0.001, \quad \mathrm{P}=0.004)(15,23)$ and different with study at Qazvin $(\mathrm{P}=0.171)(16)$.

Altogether, $51.9 \%$ of the patients had a positive family history of cancer (the presence of different cancers among the first or second-degree relatives of the patient) of whom $68.1 \%$ were in the first-degree relatives. Studies in Ardebil (west- north of Iran)(20) and Tehran (23)showed the $17.3 \%$ and $11.6 \%$ of patients had positive family history of cancer. Additionally, the most common cancers among the family members were lung $(23.7 \%)$, breast (12.6\%) and stomach (12.6\%), respectively. In a similar Turkish study,38\% of 213 patients had a positive family history of cancer, including $41.9 \%$ lung, $19 \%$ gastrointestinal, and $7.6 \%$ breast cancers(24). Although MACSA is considered as a referral center for cancer patients in central Iran, Isfahan, apparently more evaluations in future studies, with emphasis on the genetic context of the disease could be helpful. Residence of the patients was $93.1 \%$ in urban and $6.9 \%$ in rural areas (13.49 times). In one study at Teaching Hospital of Qazvin(Iran)(16), 54.2\% of patients and in the study in 
Ardebil(20), 54.1\% were urban. Since according to the last study of Statistical Center of Iran, the $85.42 \%$ and $14.57 \%$ of total population of Isfahan Province were urban and rural, respectively(25), we expect this proportion would be also among the patients with lung cancer if there is no difference between urban and rural populations regarding to the incidence rate of the disease. With comparison the results, it is revealed that the proportion of the urban patients to the rural ones is 13.49 , while it is 5.86 in Isfahan general population. It means the incidence rate of the disease in the urban population is estimated 2.3 times more than the rural populations. It may be attributed to the air pollution and other environmental cancer-related risk factors which have been accumulated in the urban regions more than rural areas. More population-based studies can evaluate this hypothesis.

\section{Histopathological features}

Overall, $63.1 \%$ of the patients had metastasis at the time of study of which $57.6 \%$ had presented metastasis at diagnosis. Common metastatic sites were bone, brain, and liver. According to one study in India(26), the rate of lung cancer metastasis was $32.5 \%$. In the study at Tehran(15) $67.3 \%$ of patients had metastasis in which the sites included contralateral lung, bone, liver, brain. According to table 2, 57.6\% patients were diagnosed in stage 4 and $21.5 \%$ in stage 3 . In the studies at Tehran(15), 85.3\% were in stages 3 to 4 , in other study at Tehran(22), 48.5\% were in Stage 4, and in the study at Sari( north of Iran) (27), $85.1 \%$ of patients were in stage 4.

In most cases of lung cancer, the disease is diagnosed in advanced stages (28). Based on this information the screening program in Iran should be paid more attention to early detection of lung cancers and making biological clues for different sites of metastasis.

According to the pathological reports (Table 3), the frequency of different types of lung cancer were $36.9 \%$ cases of adenocarcinomas, $14.2 \%$ cases of squamous cell carcinoma, 9.6\% cases of bronchogenic carcinoma and $8.1 \%$ cases small cell lung cancer, respectively. There was significant relationship between different types of lung cancer and $\quad \operatorname{sex} \quad(\mathrm{p}<0.001) . \quad$ (Figure 1$)$ In the study at Teaching Hospital of Qazvin (Iran)(16), 52.7\% of patients had SCC and 
In the study at Yazd( Iran)(8) 34.9\% of patients had SCC and In study at Tehran (23), 19\% of patients were SCC (Table 6).

According to the results, totally 93 patients (35.7\%) had IHC assay reports in which 53 different diagnostic, prognostic, and predictive biomarkers had been measured (Table 5, 7).

Although all of the measured biomarkers have a diagnostic significance (29-34), the most relevant biomarkers which have been recently identified, CK20 and CK7, have an important prognostic value in lung cancer patients(35). Moreover, predictive markers like LCA (31) has been checked in a few patients. It seems, currently, IHC tests for cancer in Iranian patients are requested for diagnostic indications than predictive ones. It may be due to the limitation of cancer molecular and genetic testing facilities in Iran. Apparently, development of new advanced cancer genetic labs along with the education of clinicians towards personalized medicine-associated approaches on cancer could promote the clinical applications of molecular cancer biomarkers in Iran.

\section{Environmental risk factors}

Smoking, is the most important lung cancer-related risk factor, so $90-85 \%$ of all lung cancers are directly caused by exposure to cigarettes (36). In our study, $49.2 \%$ of the patients were cigarette smokers with an average $35.45(\mathrm{SD}=14)$ pack per year. In other studies at Tehran, 57.2\% (15) and 72.9\%(23) and in study at Ardebil(north of Iran) (20), $90.8 \%$ were cigarette smokers with an average $25.7(\mathrm{SD}=38.67)$ pack per year. It seems other environmental factors are suspected as the underlying cause of catching lung cancer in the patients. So, we investigated other factors according to table 4 , hookah smoking, opium addiction and alcohol consumption, as the other potential reasons for catching lung cancer in the studied population. On the other hand, $125(72.6 \%)$ of men and 3 (3.4\%) of women were active cigarette smokers and there is a significant difference between sexes and cigarette smoking, hookah smoking, opium addiction and alcohol consumption $(\mathrm{p}<0.001)$. In the study at Tehran(15), $70.3 \%$ of male and $5 \%$ of female lung cancer patients were cigarette smoker. This difference is likely due to the less consumption of cigarettes among Iranian women because of the cultural reason when we compare with the other countries (23). Accordingly, we expect the male to female 
proportion among the Iranian patients with lung cancer be significantly more than other countries with high prevalence of smoking among their women. This proportion, however, is less than other countries, according to our results and their comparison with other foreign studies $(17,18)$. It could be referred to the different genetic background in our populations in comparison to the other countries and more effect of the inheritable genetic factors in pathogenesis of the disease. This conclusion may be approved by the high prevalence of familial lung cancer among the patients compared to other populations, an issue which needs more evaluations in the next studies.

In other studies of Iranian population like Teaching Hospital of Qazvin (Iran)(16), 17.2\% of the patients had opium addiction, $47.4 \%$ baking bread history, $2.4 \%$ contact with a chemical substance. In one study at Ardebil(20), 34.7\% had opium addiction and $11.3 \%$ had a history of baking bread. Totally our study suggests, instead of concentrating on cigarette consumption between lung cancer patients, we should pay more attention to the other ways of smoking (hookah and opium) and environmental exposures in Iranian patients to achieve comprehensive risk factors underlying lung cancer.

According to other studies, smoking is associated with a higher proportion of SCC. The lower prevalence of SCC in our study may be due to the lower consumption of cigarettes in the population than other populations studied in Iran. There was, also, a significant difference in the histopathologic type of lung cancer $(\mathrm{p}<0.001)$ between sexes in this study, similar to other Iranian studies $(15,16,23)$.

Due to the limitations of our study (inaccessibility to the other risk factors and comprehensive molecular study), we could not conclude any other items.

\section{Clinical aspects}

According to the results, the most common early symptoms of lung cancer among the patients were cough and dyspnea. In the Qazvin study (16), 76.5\% patients had cough as an early symptom but in the Ardebil study (20) the most common symptom was hemoptysis $(32.7 \%)$. This controversy in studies needs more comprehensive data to make an accurate decision about the early symptoms of lung cancer in Iranian patients. Altogether, $67.3 \%$ patients had a history of chemotherapy and $38.1 \%$ had a history of radiation therapy. In one study at Sari (north of Iran)(27), 57\% of the patients had 
tolerated chemotherapy. These results may be correlated to the stage of diagnosis in our patients. Curative chemotherapy and radiotherapy are more acceptable for the patients who are not in the advanced stage.

\section{Conclusion}

This study was performed on 260 patients with lung cancer who had been referred to MACSA-Isfahan within 2012-2018. The prevalence of disease was significantly more in men and in urban patients.

There was a significant difference between the mean age of women and men with lung cancer. Most of the patients had metastasis at the time of referral and bones were the most common site of metastasis. There was a significant relationship between sex and smoking. The most common histopathologic feature of lung cancer among the patients was adenocarcinoma, probably due to the lower consumption of smoking in our population. In some patients, the diagnostic and therapeutic biomarkers had been checked, and CK7 was positive in most of the cases in which the biomarker was checked. Given the limitations of this study regarding the accessibility of the patients' data and sample size, more investigations are recommended to reveal a more accurate epidemiologic and clinicohistopathologic feature of the disease and its risk factors in central Iran.

\section{ACKNOWLEDGEMENTS}

The authors declare the full gratitude of the health-workers in MACSA center, as well as the Student Research Committee at the Isfahan University of medical sciences. 


\section{References}

1. Ferlay J, Shin H-R, Bray F, Forman D, Mathers C, Parkin DM. Estimates of worldwide burden of cancer in 2008: GLOBOCAN 2008. Int J Cancer. 2010 Dec 15;127(12):2893917.

2. Saadat S, Yousefifard M, Asady H, Moghadas Jafari A, Fayaz M, Hosseini M. The Most Important Causes of Death in Iranian Population; a Retrospective Cohort Study. Emergency. 2015;3(1):16-21.

3. FARHOOD B, GERAILY G, ALIZADEH A. Incidence and Mortality of Various Cancers in Iran and Compare to Other Countries: A Review Article. Iran J Public Health. 2018 Mar;47(3):309-16.

4. Zhang M, Wu C-H, Zhu X-L, Wang Y-J. Loss of imprinting of insulin-like growth factor 2 is associated with increased risk of primary lung cancer in the central China region. Asian Pac J Cancer Prev APJCP. 2014;15(18):7799-803.

5. Jemal A, Bray F, Center MM, Ferlay J, Ward E, Forman D. Global cancer statistics. CA Cancer J Clin. 2011 Mar 1;61(2):69-90.

6. Cancer Statistics Review, 1975-2014 - SEER Statistics [Internet]. SEER. [cited 2018 Nov 29]. Available from: https://seer.cancer.gov/archive/csr/1975_2014/

7. Bosetti C, Bertuccio P, Levi F, Lucchini F, Negri E, La Vecchia C. Cancer mortality in the European Union, 1970-2003, with a joinpoint analysis. Ann Oncol Off J Eur Soc Med Oncol. 2008 Apr;19(4):631-40.

8. Zahir ST, Mirtalebi M. Survival of patients with lung cancer, Yazd, Iran. Asian Pac J Cancer Prev APJCP. 2012;13(9):4387-91.

9. Types of Lung Cancer: Small Cell and Non-Small Cell Lung Cancer Types [Internet]. [cited 2018 Nov 29]. Available from: https://www.webmd.com/lung-cancer/lung-cancer-types\#1

10. de Groot P, Munden RF. Lung cancer epidemiology, risk factors, and prevention. Radiol Clin North Am. 2012 Sep;50(5):863-76.

11. Rosai and Ackerman's Surgical Pathology - 2 Volume Set - 10th Edition [Internet]. [cited 2018 Sep 22]. Available from: https://www.elsevier.com/books/rosai-and-ackermanssurgical-pathology-2-volume-set/rosai/978-0-323-06969-4

12. Almasi Z, Salehiniya H, Amoori N, Enayatrad M. Epidemiology Characteristics and Trends of Lung Cancer Incidence in Iran. Asian Pac J Cancer Prev APJCP. 2016;17(2):557-62. 
13. Siegel R, Naishadham D, Jemal A. Cancer statistics, 2013. CA Cancer J Clin. 2013 Jan;63(1):11-30.

14. Mousavi SM, Gouya MM, Ramazani R, Davanlou M, Hajsadeghi N, Seddighi Z. Cancer incidence and mortality in Iran. Ann Oncol Off J Eur Soc Med Oncol. 2009 Mar;20(3):55663.

15. Adnan K, Zahra E-M, Sharareh S, Shirin K, Habib E, Kian K. Clinicopathological Characteristics of Iranian Patients with Lung Cancer: a Single Institute Experience. :6.

16. Hajmanoochehri F, Mohammadi N, Zohal MA, Sodagar A, Ebtehaj M. Epidemiological and clinicopathological characteristics of lung cancer in a teaching hospital in Iran. Asian Pac J Cancer Prev APJCP. 2014;15(6):2495-500.

17. Santos-Martínez MJ, Curull V, Blanco ML, Macià F, Mojal S, Vila J, et al. Lung Cancer at a University Hospital: Epidemiological and Histological Characteristics of a Recent and a Historical Series. Arch Bronconeumol Engl Ed. 2005 Jun;41(6):307-12.

18. Dey A, Biswas D, Saha SK, Kundu S, Kundu S, Sengupta A. Comparison study of clinicoradiological profile of primary lung cancer cases: An Eastern India experience. Indian J Cancer. 2012 Jan 1;49(1):89.

19. Hosseini M, Naghan PA, Karimi S, SeyedAlinaghi S, Bahadori M, Khodadad K, et al. Environmental risk factors for lung cancer in Iran: a case-control study. Int J Epidemiol. 2009 Aug 1;38(4):989-96.

20. Ghobadi H, Sharghi A, Sadat-Kermani Zh. Epidemiology and Risk Factors for Lung Cancer in Ardabil, Iran. Journal of Ardabil University of Medical Sciences.2013 Jun 15;13(2):2208.

21. Noronha V, Dikshit R, Raut N, Joshi A, Pramesh CS, George K, et al. Epidemiology of lung cancer in India: focus on the differences between non-smokers and smokers: a singlecentre experience. Indian J Cancer. 2012 Mar;49(1):74-81.

22. Cancer in Canada: Focus on Lung, Colorectal, Breast and Prostate [Internet]. [cited 2019 Apr 1]. Available from: https://www150.statcan.gc.ca/n1/pub/82-624X/2011001/article/11596-eng.htm

23. Hosseini M, Naghan PA, Karimi S, SeyedAlinaghi S, Bahadori M, Khodadad K, et al. Environmental risk factors for lung cancer in Iran: a case-control study. Int J Epidemiol. 2009 Aug 1;38(4):989-96.

24. (PDF) The changing epidemiological trends for carcinoma of the lung in Turkey [Internet]. ResearchGate. [cited 2019 Mar 7]. Available from: 
https://www.researchgate.net/publication/5398954_The_changing_epidemiological_trends_ for_carcinoma_of_the_lung_in_Turkey

25. WebCite query result [Internet]. [cited 2019 May 6]. Available from: http://www.webcitation.org/6CvbN9BL9

26. al MS et. Clinico-pathology of lung cancer in a regional cancer center in Northeastern India. - PubMed - NCBI [Internet]. [cited 2019 Mar 7]. Available from: https://www.ncbi.nlm.nih.gov/pubmed/24460288

27. Abedi S, Janbabaee G, Moosazadeh M, Alashti MR, Alizadeh-Navaei R, HedayatizadehOmran A. Epidemiology of Lung Cancer Patients Attending Tooba Clinic and Imam Khomeini Hospital, Sari, Iran 2010-2014. :8.

28. Silvestri GA, Alberg AJ, Ravenel J. The changing epidemiology of lung cancer with a focus on screening. BMJ. 2009 Aug 17;339:b3053.

29. Cowan ML, Li QK, Illei PB. CDX-2 Expression in Primary Lung Adenocarcinoma. Appl Immunohistochem Mol Morphol AIMM. 2016 Jan;24(1):16-9.

30. He P, Kuhara H, Tachibana I, Jin Y, Takeda Y, Tetsumoto S, et al. Calretinin mediates apoptosis in small cell lung cancer cells expressing tetraspanin CD9. FEBS Open Bio. 2013;3:225-30.

31. Majem M, Rudin CM. Small-cell lung cancer in the era of immunotherapy. Transl Lung Cancer Res. 2017 Dec;6(Suppl 1):S67-70.

32. Argon A, Nart D, Veral A. The Value of Cytokeratin 5/6, p63 and Thyroid Transcription Factor-1 in Adenocarcinoma, Squamous Cell Carcinoma and Non-Small-Cell Lung Cancer of the Lung. Turk Patoloji Derg. 2015;31(2):81-8.

33. Inamura K. Update on Immunohistochemistry for the Diagnosis of Lung Cancer. Cancers. 2018 Mar 14;10(3).

34. Woo JS, Reddy OL, Koo M, Xiong Y, Li F, Xu H. Application of Immunohistochemistry in the Diagnosis of Pulmonary and Pleural Neoplasms. Arch Pathol Lab Med. 2017 Sep;141(9):1195-213.

35. Luo H-T, Liang C-X, Luo R-C, Gu W-G. Identification of relevant prognostic values of cytokeratin 20 and cytokeratin 7 expressions in lung cancer. Biosci Rep. 2017 Dec 22;37(6).

36. Kazemi-Lomedasht F, Rami A, Zarghami N. Comparison of inhibitory effect of curcumin nanoparticles and free curcumin in human telomerase reverse transcriptase gene expression in breast cancer. Adv Pharm Bull. 2013;3(1):127-30. 


\section{Tables and Figures}

Table 1: The site of cancers among the family members of the patients with lung cancer registered in MACSA-Isfahan within 2012-2018

\begin{tabular}{|c|c|c|c|}
\hline The site of cancer & $\begin{array}{c}\text { Frequency of } \\
\text { affected members }\end{array}$ & $\begin{array}{c}\text { Percent } \\
\text { (percent in total } 260 \text { patients) }\end{array}$ & $\begin{array}{c}\text { Valid percent } \\
\text { (percent in total } 135 \text { patients) }\end{array}$ \\
\hline Lung & 32 & 12.3 & 23.7 \\
\hline Breast & 17 & 6.5 & 12.6 \\
\hline Stomach & 17 & 6.5 & 12.6 \\
\hline Colorectal & 13 & 5.2 & 9.1 \\
\hline Brain & 12 & 4.6 & 8.9 \\
\hline Hematopoietic tract & 12 & 4.8 & 8.4 \\
\hline Liver & 10 & 3.8 & 7.4 \\
\hline Prostate & 10 & 3.8 & 7.4 \\
\hline Small Intestine & 9 & 3.5 & 6.7 \\
\hline Uterine & 7 & 2.7 & 5.2 \\
\hline Skin & 6 & 2.4 & 4.2 \\
\hline Larynx & 4 & 1.5 & 3.0 \\
\hline Pancreas & 4 & 1.5 & 3.0 \\
\hline Esophagus & 2 & 0.8 & 1.5 \\
\hline MUO & 1 & 0.4 & 0.7 \\
\hline Kidney & 1 & 0.4 & 0.7 \\
\hline Testis & 1 & 0.4 & 0.7 \\
\hline Salivary glands & 1 & 0.4 & 0.7 \\
\hline
\end{tabular}


Table 2: The Frequency of histopathological TNM tumor stage at the time of diagnosis in the patients with lung cancer registered in MACSA-Isfahan within 2012-2018

\begin{tabular}{|c|c|c|}
\hline TNM tumor stage & Frequency & Percent \\
\hline stage 4 & 150 & 57.6 \\
\hline stage 3 & 56 & 21.5 \\
\hline stage 2 & 43 & 16.5 \\
\hline stage 1 & 11 & 4.2 \\
\hline Total & 260 & 100.0 \\
\hline
\end{tabular}


Table 3: The frequency of different histopathological types of lung cancer in the patients with lung cancer registered in MACSA-Isfahan within 2012-2018

SCC: Squamous Cell Carcinoma

SCLC: Small cell lung cancer

NSCLC: Non-small cell lung cancer

\begin{tabular}{|l|c|c|}
\hline histopathological type & Frequency & Percent \\
\hline Adenocarcinoma $^{1}$ & 96 & 36.9 \\
\hline SCC $^{1}$ & 37 & 14.2 \\
\hline unknown $^{4}$ & 26 & 10.0 \\
\hline Bronchogenic carcinoma $^{3}$ & 25 & 9.6 \\
\hline SCLC $^{2}$ & 21 & 8.1 \\
\hline Sarcomatoid carcinoma & \\
\hline Neuroendocrine & 18 & 6.9 \\
\hline carcinoma $^{3}$ & 12 & 4.6 \\
\hline Mesotheliuma $^{3}$ & 11 & 4.2 \\
\hline NSCLC $^{1}$ & 9 & 3.5 \\
\hline Lymphoma $^{3}$ & 3 & 1.2 \\
\hline Large cell carcinoma $^{1}$ & 2 & .8 \\
\hline Total $^{1}$ & 260 & 100.0 \\
\hline
\end{tabular}

1: NSCLC 2: SCLC 3: Other types of lung cancer 4: Unknown 
Table 4: The exposure rate with some of the environmental factors in the patients with lung cancer registered in MACSA-Isfahan within 2012-2018

SCLC: Small cell lung cancer

NSCLC: Non-small cell lung cancer

\begin{tabular}{cccccc} 
Risk Factor & NSCLC & SCLC & Other & Un known & $\begin{array}{c}\text { Total } \\
\text { number (\%) }\end{array}$ \\
\hline $\begin{array}{c}\text { Cigarette } \\
\text { smoking }\end{array}$ & $68(52.7 \%)$ & $14(73.6 \%)$ & $40(46.5 \%)$ & $6(23.0 \%)$ & $128(49.2 \%)$ \\
\hline $\begin{array}{c}\text { Passive } \\
\text { smoker }\end{array}$ & $23(17.8 \%)$ & $2(10.52 \%)$ & $19(22.09 \%)$ & $7(26.92 \%)$ & $51(19.61 \%)$ \\
\hline $\begin{array}{c}\text { Hookah } \\
\text { smoking }\end{array}$ & $52(40.3 \%)$ & $12(63.1 \%)$ & $33(38.37 \%)$ & $4(15.38 \%)$ & $101(38.8 \%)$ \\
\hline $\begin{array}{c}\text { Opium } \\
\text { addiction }\end{array}$ & $40(31 \%)$ & $8(42.1 \%)$ & $17(19.76 \%)$ & $1(3.84 \%)$ & $66(25.38 \%)$ \\
\hline $\begin{array}{c}\text { Alcoholic } \\
\text { drinker }\end{array}$ & $9(6.97 \%)$ & 0 & $3(3.48 \%)$ & $1(3.84 \%)$ & $13(5 \%)$ \\
\hline $\begin{array}{c}\text { Cooking } \\
\text { bread }\end{array}$ & $11(8.52 \%)$ & 0 & $7(8.1 \%)$ & $3(11.53 \%)$ & $21(8 \%)$ \\
\hline $\begin{array}{c}\text { Carpet } \\
\text { weaving }\end{array}$ & $12(9.30 \%)$ & 0 & $9(10.4 \%)$ & $2(7.69 \%)$ & $23(8.84 \%)$ \\
\hline $\begin{array}{c}\text { Chemical } \\
\text { substance }\end{array}$ & $23(17.82 \%)$ & $3(15.7 \%)$ & $16(18.6 \%)$ & $2(7.69 \%)$ & $44(16.92 \%)$ \\
\hline $\begin{array}{c}\text { Asbestosis } \\
\text { Total }\end{array}$ & $1(0.77 \%)$ & 0 & $1(1.16 \%)$ & 0 & $2(0.7 \%)$ \\
\hline 129 & 19 & 86 & 26 & \\
\hline & & & & & \\
\hline & & & & & \\
\hline
\end{tabular}


Table 5: The frequency distribution of the lung cancer patients according to the molecular biomarkers checked on their tumor samples

\begin{tabular}{|c|c|c|c|c|c|}
\hline \multirow[t]{2}{*}{ valid } & \multicolumn{2}{|c|}{ Frequency } & \multirow{2}{*}{$\begin{array}{l}\text { Biomarker } \\
\text { frequency } \\
\text { unavailable } \\
\text { data }\end{array}$} & \multirow{2}{*}{$\begin{array}{c}\text { Percent } \\
\text { of } \\
\text { positive }\end{array}$} & \multirow{2}{*}{$\begin{array}{c}\text { Valid } \\
\text { percent of } \\
\text { positive }\end{array}$} \\
\hline & positive & negative & & & \\
\hline CK7 & 48 & 6 & 206 & 18.5 & 88.9 \\
\hline TTF1 & 42 & 17 & 201 & 16.2 & 71.2 \\
\hline PR & 0 & 3 & 257 & 0 & 0 \\
\hline CK5 & 4 & 3 & 253 & 1.5 & 57.1 \\
\hline CK20 & 11 & 37 & 212 & 4.2 & 22.9 \\
\hline CD56 & 0 & 8 & 252 & 0 & 0 \\
\hline CD19 & 0 & 1 & 259 & 0 & 0 \\
\hline $\mathrm{CD} 20$ & 3 & 9 & 248 & 1.2 & 25.0 \\
\hline CD3 & 2 & 4 & 254 & 0.8 & 33.3 \\
\hline CD7 & 0 & 1 & 259 & 0 & 0 \\
\hline CD33 & 1 & 0 & 259 & 0.4 & 100.0 \\
\hline CD68 & 1 & 0 & 259 & 0.4 & 100.0 \\
\hline AE1/AE3 & 1 & 0 & 259 & 0.4 & 100.0 \\
\hline $\mathrm{TG}$ & 0 & 1 & 259 & 0 & 0 \\
\hline CD99 & 5 & 1 & 254 & 1.9 & 83.3 \\
\hline CALRETININ & 4 & 14 & 242 & 1.5 & 22.2 \\
\hline CD34 & 2 & 1 & 257 & 0.8 & 66.7 \\
\hline $\mathrm{S} 100$ & 2 & 4 & 254 & 0.8 & 33.3 \\
\hline DESMIN & 2 & 4 & 254 & 0.8 & 33.3 \\
\hline BCL2 & 2 & 1 & 257 & 0.8 & 66.7 \\
\hline CD117 & 1 & 3 & 256 & 0.4 & 25.0 \\
\hline CYTOCERATIN7/20 & 0 & 1 & 259 & 0 & 0 \\
\hline NSE & 5 & 0 & 255 & 1.9 & 100.0 \\
\hline
\end{tabular}




\begin{tabular}{|c|c|c|c|c|c|}
\hline EMA & 3 & 2 & 255 & 1.2 & 60.0 \\
\hline CYTOCIN20 & 1 & 0 & 259 & 0.4 & 100.0 \\
\hline GCDFP15 & 0 & 2 & 258 & 0 & 0 \\
\hline CD10 & 1 & 1 & 258 & 0.4 & 50.0 \\
\hline CK6 & 4 & 4 & 252 & 1.5 & 50.0 \\
\hline CA125 & 0 & 4 & 256 & 0 & 0 \\
\hline ALK1 & 0 & 1 & 259 & 0 & 0 \\
\hline EGFR & 2 & 2 & 256 & 0.8 & 50.0 \\
\hline CD5 & 1 & 3 & 256 & 0.4 & 25.0 \\
\hline TDT & 1 & 1 & 258 & 0.4 & 50.0 \\
\hline WT1 & 2 & 10 & 248 & 0.8 & 16.7 \\
\hline CEA & 5 & 6 & 249 & 1.9 & 45.5 \\
\hline GATA3 & 1 & 4 & 255 & 0.4 & 20.0 \\
\hline VIMENTIN & 6 & 6 & 248 & 2.3 & 50.0 \\
\hline CHOROMOGRANIN & 13 & 7 & 240 & 5.0 & 65.0 \\
\hline SYNAPTOPHYSIN & 15 & 4 & 241 & 5.8 & 78.9 \\
\hline $\mathrm{P} 63$ & 9 & 7 & 244 & 3.5 & 56.3 \\
\hline $\mathrm{CDX} 2$ & 1 & 18 & 241 & 0.4 & 5.3 \\
\hline $\mathrm{CK}$ & 21 & 7 & 232 & 8.1 & 75.0 \\
\hline CK8 & 1 & 0 & 259 & 0.4 & 100.0 \\
\hline CK18 & 1 & 0 & 259 & 0.4 & 100.0 \\
\hline ER & 1 & 7 & 252 & 0.4 & 12.5 \\
\hline CD56 & 2 & 0 & 258 & 0.8 & 100.0 \\
\hline GFAP & 0 & 1 & 259 & 0 & 0 \\
\hline LCA & 4 & 11 & 245 & 1.5 & 26.7 \\
\hline NAPSINE & 5 & 1 & 254 & 1.9 & 83.3 \\
\hline PSA & 0 & 3 & 257 & 0 & 0 \\
\hline SMA & 1 & 0 & 259 & 0.4 & 100.0 \\
\hline MELAN A & 0 & 1 & 259 & 0 & 0 \\
\hline
\end{tabular}




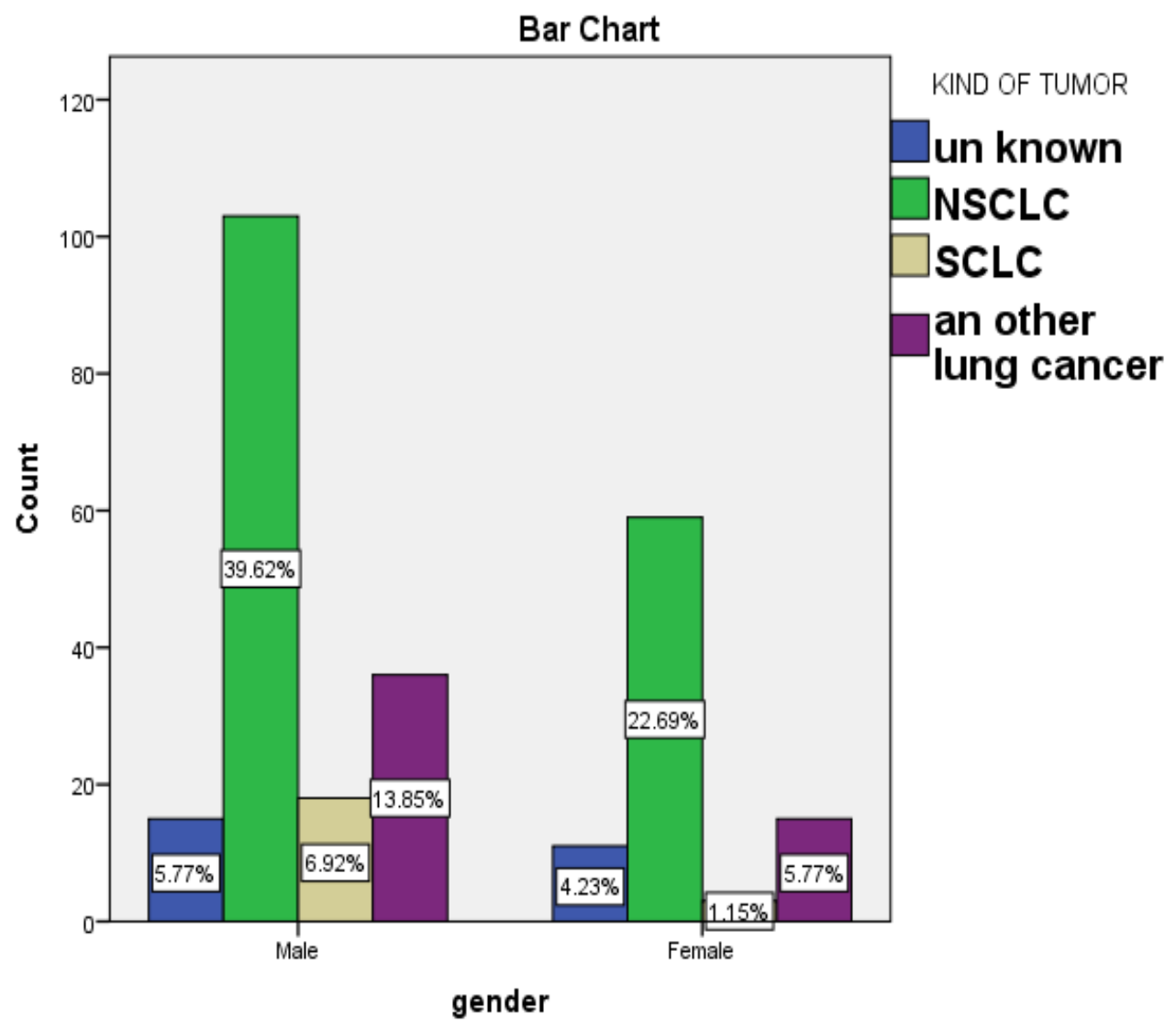

Figure 1: The frequency distribution of different types of lung cancer according to the sex, in the patients registered in MACSA-Isfahan within 2012-2018

SCLC: Small cell lung cancer

NSCLC: Non-small cell lung cancer 
Table 6: The frequency of histopathologic types of lung cancer in the current study and other similar studies in Iran.

\begin{tabular}{|ccccccc|}
\hline histopathologic type & $\begin{array}{c}\text { Current } \\
\text { study }\end{array}$ & $\begin{array}{l}\text { Tehran } \\
\text { study(15) }\end{array}$ & $\begin{array}{l}\text { Ardebil } \\
\text { study(20) }\end{array}$ & $\begin{array}{l}\text { Tehran } \\
\text { study(23) }\end{array}$ & $\begin{array}{l}\text { Qazvin } \\
\text { study(16) }\end{array}$ & Yazd study(8) \\
\hline $\begin{array}{c}\text { Adenocarcinoma } \\
\text { (AC) }\end{array}$ & $36.9 \%$ & $45.01 \%$ & $14.5 \%$ & $28.9 \%$ & $14.8 \%$ & $23.5 \%$ \\
\hline $\begin{array}{c}\text { Squamous cell } \\
\text { carcinoma(SCC) }\end{array}$ & $14.2 \%$ & $23.28 \%$ & $61.3 \%$ & $19 \%$ & $52.7 \%$ & $34.9 \%$ \\
\hline $\begin{array}{c}\text { Small cell lung } \\
\text { cancer(SCLC) }\end{array}$ & $8.1 \%$ & $16.93 \%$ & $16.9 \%$ & $18.6 \%$ & $13.3 \%$ & $22 \%$ \\
\hline
\end{tabular}


Table 7: The most relevant biomarkers that have been checked in the patients with lung cancer registered in MACSA-Isfahan within 2012-2018

\begin{tabular}{|c|c|c|c|}
\hline Biomarker & $\begin{array}{l}\text { Total number of checked } \\
\text { biomarker (percent in } \\
\text { total } 93 \text { Patients) }\end{array}$ & $\begin{array}{l}\text { Number of Positive } \\
\text { (percent) }\end{array}$ & $\begin{array}{c}\text { Number of } \\
\text { Negative(percent) }\end{array}$ \\
\hline CK20*\&** & $60(64.5 \%)$ & $14(23.3 \%)$ & $46(76.6 \%)$ \\
\hline TTF1 $^{*}$ & $59(63.4 \%)$ & $42(71.1 \%)$ & $17(28.8 \%)$ \\
\hline $\mathrm{CK}^{* \&^{* *}}$ & $54(58 \%)$ & $48(88.8 \%)$ & $6(11.1 \%)$ \\
\hline CK5/6* & $28(30.1 \%)$ & $21(75 \%)$ & $7(25 \%)$ \\
\hline Chromogranin* & $20(21.5 \%)$ & $13(65 \%)$ & $7(35 \%)$ \\
\hline Synaptophysin* & $19(20.4 \%)$ & $15(78.9 \%)$ & $4(21 \%)$ \\
\hline $\mathrm{CDX}^{*}$ & $19(20.4 \%)$ & $1(5.2 \%)$ & $18(94.7 \%)$ \\
\hline Calretinin $^{*}$ & $18(19.3 \%)$ & $4(22.2 \%)$ & $14(77.7 \%)$ \\
\hline P63* & $16(17.2 \%)$ & $9(56.2 \%)$ & $7(43.7 \%)$ \\
\hline $\mathrm{LCA}^{* * *}$ & $15(16.1 \%)$ & $4(26.6 \%)$ & $11(73.3 \%)$ \\
\hline VIMENTIN $^{* *}$ & $12(12.9 \%)$ & $6(50 \%)$ & $6(50 \%)$ \\
\hline $\mathrm{WT} 1^{* *}$ & $12(12.9 \%)$ & $2(16.6 \%)$ & $10(83.3 \%)$ \\
\hline $\mathrm{CEA}^{* *}$ & $11(11.8 \%)$ & $5(45.4 \%)$ & $6(54.5 \%)$ \\
\hline
\end{tabular}

$*$ the diagnostic biomarkers. ${ }^{* *}$ the prognostic biomarkers. $* * *$ the predictive biomarkers. $(29,33$, 36,37 ) 